\title{
Seasonal variation in gonadal steroids of males and females in the Cape mole-rat (Georychus capensis): the potential for opportunistic breeding
}

\author{
M.K. Oosthuizen* \& N.C. Bennett \\ Mammal Research Institute, Department of Zoology and Entomology, University of Pretoria, \\ Pretoria, 0002 South Africa \\ Received 15 September 2008. Accepted 2 March 2009
}

\begin{abstract}
Urinary testosterone concentrations in males and urinary progesterone and oestradiol concentrations in females were measured in the Cape mole-rat (Georychus capensis) and compared for the summer and winter periods. The Cape mole-rat breeds seasonally, with sexual activity and subsequent pregnancy recorded during the winter months in the southern hemisphere. Despite the fact that it has a distinct breeding season, seasonal differences in urinary hormone concentrations of both male and female Cape mole-rats were not statistically significant. This finding supports the notion the Cape mole-rat may have the opportunity to operate as an opportunistic breeder if fortuitous environmental conditions arise, such as unseasonal rainfall, occurring at these normally non-favourable times of the year.
\end{abstract}

Key words: Cape mole-rat, progesterone, testosterone, oestrogen, seasonal breeding.

\section{INTRODUCTION}

The Cape mole-rat (Georychus capensis) is a solitary rodent mole that is xenophobic and highly aggressive towards conspecifics (Nevo 1979; Bennett \& Jarvis 1988). Foot drumming is used to convey information about territorial boundaries, such that neighbouring tunnel systems may come to within a metre of one another but do not interlink (Bennett \& Jarvis 1988).

Aggressive and territorial behaviour is halted briefly during courtship and mating. This behaviour is initiated via foot drumming that, depending on the frequency, relates information about sex and reproductive state to surrounding conspecifics (Bennett \& Jarvis 1988). In the Cape mole-rat, breeding is restricted to the wet winter months. Mole-rats have a relatively long gestation time for their body size (Bennett \& Faulkes 2000), such that young are produced towards the end of the winter and into early spring. The Cape mole-rat appears to have the potential to produce two litters per season (Bennett \& Jarvis 1988).

The Cape mole-rat is an induced ovulator, and thus does not show a constant cyclical pattern of ovulation (Van Sandwyk \& Bennett 2005). The act of coitus stimulates the hypothalamus to produce $\mathrm{GnRH}$, which in turn, triggers the release of follicle stimulating hormone (FSH) from the anterior pituitary. FSH promotes follicular development, from where oestrogen is secreted. The increasing levels of oestrogen arising from follicular development produce a surge of $\mathrm{LH}$ with subsequent ovulation (Knobil 1988).

In most seasonally breeding mammals, the reproductive system undergoes some degree of regression during the reproductively quiescent season. In seasonally breeding females, ovulation occurs only during those parts of the year that are optimal for reproduction, whereas in males testicular size is reduced and sperm production is down-regulated or terminated. Furthermore, gonadal steroid levels are secreted at much lower levels (Gerlach \& Aurich 2000). The Cape mole-rat breeds seasonally, but to date there are no data on gonadal steroid hormone profiles for wildcaptured individuals both during the breeding season (August) and out of the breeding season (February); the only study previously reported was based on a pair of mole-rats housed in captivity (Bennett \& Jarvis, 1988). The aim of this study was to determine whether there is a seasonal difference in urinary steroid concentrations in males and females, respectively.

\section{MATERIALS \& METHODS}

Cape mole-rats were captured using modified Hickman live traps baited with sweet potato 
(Hickman 1979). The study area was approximately $3 \mathrm{~km}$ south of Darling in the Western Cape Province, South Africa $\left(33^{\circ} 22^{\prime} \mathrm{S}, 15^{\circ} 25^{\prime} \mathrm{E}\right)$, The mole-rats were trapped in August, during the breeding season, and in February, during the non-breeding season. Animals were maintained in the laboratory at Pretoria for a period of three weeks, where they were housed in plastic containers lined with wood shavings in climate rooms at $25^{\circ} \mathrm{C}$ with a 12L:12D light cycle. They were fed a diet of chopped sweet potatoes, carrots and gem squash. No free water was provided as moisture is obtained from food. One urine sample per animal was collected, within two weeks of capture. Urine hormone concentrations were measured, rather than serum concentrations, as urine collections is not invasive and therefore less stressful to the animals.

The mean body mass ( \pm S.E.M.) of adult male Cape mole-rats captured during the breeding season was $170 \pm 19.7 \mathrm{~g}(n=5)$, while for females during the breeding season it was $134 \pm 11.1 \mathrm{~g}$ $(n=14)$. Pregnant females were not included in any calculations. During the non-breeding season, mean body mass of adult male Cape mole-rats was $129 \pm 18 \mathrm{~g}(n=4)$ and for females it was $162 \pm$ $14.5 \mathrm{~g}(n=12)$. In the field, males were encountered much less frequently than females.

\section{Radioimmunoassays}

Testosterone determination. Plasma testosterone concentrations were determined using a Coat-ACount total testosterone kit (Diagnostic Products Corporation, Los Angeles, California, U.S.A.). Extraction or chromatography was not required for this procedure. A $50 \mu \mathrm{l}$ urine sample in duplicate was used for the assay. The procedure entails solid-phase radioimmunoassay based on hormone specific antibody immobilized to the wall of a polypropylene tube. ${ }^{125}$ I-labeled testosterone competes for a fixed time with the specific hormone in the given sample for antibody sites. The tube is then decanted to separate bound from free and is then counted in a Cobra gamma counter.

The antiserum is highly specific for testosterone and has a low cross reactivity with other naturally occurring steroids except dihydrotestosterone, which is less than $5 \%$. The assay was validated by testing for parallelism using serial doubling dilutions of unextracted plasma over the dilution range (1:1 to $1: 64)$. The slope of the lines were compared and found not to differ significantly (ANCOVA $F_{(1,6)}=4.3 P>0.05$ ) following a log-logit data transformation (Chard 1987).
The sensitivity of the assay ( $90 \%$ binding) was $2.2 \mathrm{nmol} / \mathrm{l}$. The intra-assay coefficient of variation was $2.5 \%(n=6)$.

Oestrogen determination. Oestradiol-17 $\beta$ was determined in mole-rat urine using a Coat-ACount Oestradiol-17 $\beta$ kit (Diagnostic Products Corporation, Los Angeles, California, U.S.A.). A $100 \mu$ l sample in duplicate was used for this assay. The method is a solid-phase radioimmunoassay that does not require purification of steroids or separation by chromatography. The antiserum is highly specific for oestradiol- $17 \beta$, with a low cross reactivity with any other steroids present in the urine. The assay was validated by testing for parallelism using serial doubling dilutions of un-extracted urine over the dilution range (1:1 to 1:64) following log-logit transformation of the data (Chard 1987). The slope of the lines were compared and found not to differ significantly $\left(\right.$ ANCOVA $\left.F_{(1,6)}=0.09, P>0.05\right)$. The sensitivity of the assay was $2 \mathrm{pmol} / \mathrm{l}$. The intra-assay coefficient of variation was $9 \%(n=8)$.

Progesterone determination. Urinary progesterone concentrations were determined using a Coat-ACount progesterone radioimmunoassay kit (Diagnostic Products Corporation, Los Angeles, California, U.S.A.), as described by Bennett $e t$ al. (1996). A volume of 100:1 of urine in duplicate was assayed without extraction.

The antiserum is highly specific for progesterone with a low cross reactivity to all other naturally occurring steroids except 20- $\alpha$-dihydroprogesterone and 11-deoxycortisol with a cross reactivity of $2 \%$ and $2.4 \%$, respectively. A pooled urine sample (one with expected high concentrations from a pregnant queen) was double diluted from 1:1 to 1:64 and assayed.

In the assay were also included six samples at a dilution of 1:64 from a pool of low concentration progesterone. To these samples $100 \mu \mathrm{l}$ of progesterone in increasing concentrations $(0.3,1.6,6.4$, $31.8,63.6$ and $120 \mathrm{nmol} / \mathrm{l}$ ) was added in duplicate. The curve was perfectly parallel to the standard curve. The assay was validated for the test species by comparing the slope of the curve produced using serial doubling dilutions of un-extracted mole-rat urine (over the range 1:1 to 1:64) against the standard curve $\left(\operatorname{ANCOVA} F_{(1,6)}=4.9, P>0.05\right.$ ). The intra and inter assay coefficients of variation were 7 and $11 \%$ respectively. The sensitivity of the assay at $90 \%$ binding was $0.4 \mathrm{nmol} / \mathrm{l}$.

Creatinine determination. Urine concentration varies with fluid consumption; therefore creatinine 
is used to standardize samples. Creatinine is a breakdown product from tissue proteins and is excreted at a relatively constant rate (SchmidtNielsen 1997).

A modified Jaffe reaction was used to calculate the creatinine concentration for urine samples (Folin 1914).

The samples were assayed in duplicate. Ten microlitres of standard or sample were added to the wells of a micro plate, leaving two wells empty as a blank control. $200 \mu \mathrm{l}$ of picric reagent was added to all the wells, including the blanks. The picric reagent consisted of saturated picric acid solution, alkaline triton solution $(4.2 \mathrm{ml}$ triton

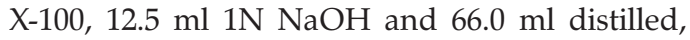
deionized water) and distilled deionized water in the proportion of 1:1:10. The alkaline triton can only be used once the product is homogenous. The microplate was then placed in the dark for a period of 1.5 hours, at room temperature, to allow colour development to occur. A standard curve $\left(R^{2}>0.99\right)$ was used to determine all sample values.

\section{Statistical analysis}

The statistical program Statistica was used for statistical analysis. As a result of small sample sizes of some of the groups, non-parametric Mann Whitney $U$-tests were performed on the different experimental groups to discover any significant differences between them.

\section{RESULTS}

\section{Testosterone}

Urinary testosterone concentrations in male Cape mole-rats were slightly higher during the breeding season (winter) compared to out of the breeding season (summer), but the difference was not significant (Mann Whitney $U$-test: $n_{1}=4$, $\left.n_{2}=5, U=7, Z=0.735, P=0.462\right)$ (Fig. 1).

\section{Oestrogen}

The urinary oestrogen concentrations in female Cape mole-rats were higher during the breeding season (winter) than out of the breeding season (summer). This difference, however, was not statistically significant (Mann Whitney $U$-test: $n_{1}=$ 14, $n_{2}=12, U=50, Z=1.75, P=0.08$ ) (Fig. 2).

\section{Progesterone}

The female Cape mole-rats have a higher concentration of urinary progesterone during the

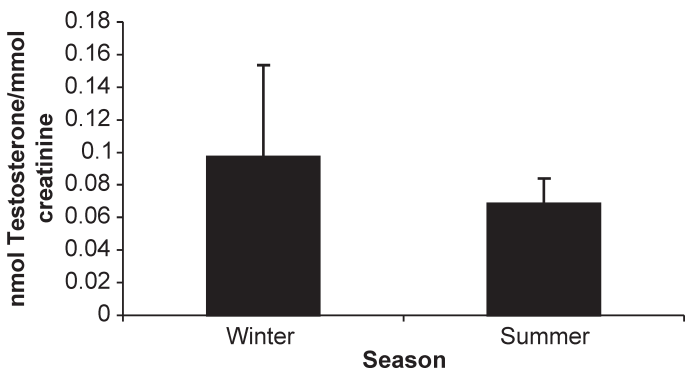

Fig. 1. Urinary testosterone concentrations $(\mathrm{nmol} / \mathrm{mmol}$ creatinine) measured in and out of the breeding season in male Cape mole-rats.

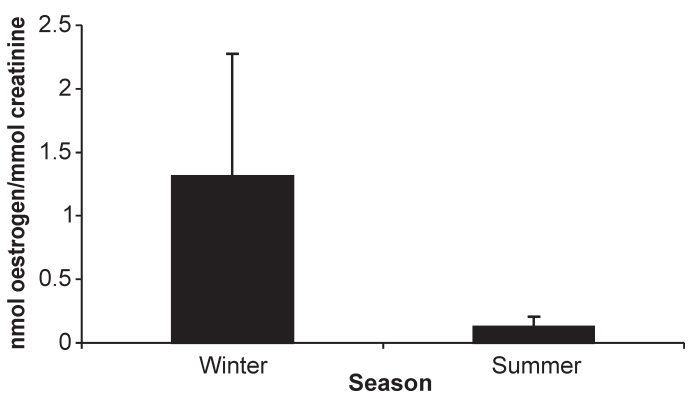

Fig. 2. Urinary oestrogen concentrations $(\mathrm{nmol} / \mathrm{mmol}$ creatinine) measured in and out of the breeding season in female Cape mole-rats.

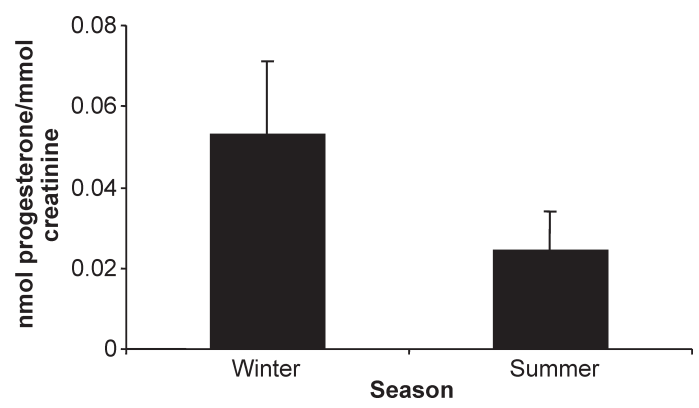

Fig. 3. Urinary progesterone concentrations $(\mathrm{nmol} / \mathrm{mmol}$ creatinine) measured in and out of the breeding season in female Cape mole-rats.

breeding season (winter) compared to out of the breeding season (summer); however, this difference was not significant (Mann Whitney $U$-test: $n_{1}=14$, $n_{2}=12, U=51, Z=1.69, P=0.089$ ) (Fig. 3).

\section{DISCUSSION}

Seasonal breeding is the norm amongst solitary subterranean rodents (Andersen \& MacMahon 1981; Bennett \& Jarvis 1988; Hansen 1960; Herbst et al. 2004; Jarvis 1969; Rado et al. 1992; Vaughan 1962). As a result, young are produced at a time of 
the year that is optimal for their survival. Typically, the reproductive state of seasonally breeding animals is reflected in the physiology of their reproductive systems (Clarke 1981). Reproductive function is usually disrupted during periods when environmental conditions are unfavourable for breeding. In general, ovulation is suspended in females, whereas sperm production and its quality is affected in males (Gerlach \& Aurich 2000). Gonadotrophin releasing hormone $(\mathrm{GnRH})$ plays a key role in reproductive function, and gonadal steroids both stimulate and inhibit its release. Negative feedback from gonadal hormones mainly reduces pulse frequency of $\mathrm{GnRH}$ release, which imposes an inhibitory effect downstream on the rest of the reproductive system. Gonadal hormone concentrations that, outside of the breeding season, inhibit $\mathrm{GnRH}$ secretion have no effect or are stimulatory during the breeding season (Karsch et al. 1984, 1993; Lincoln 1984). Changes in gonadal steroid feedback are at least partly responsible for seasonal changes observed in GnRH release (Ebling et al. 1994).

In wild-captured male Cape mole-rats, urinary testosterone concentrations were not significantly higher during the breeding season (winter) than in the non-breeding season (summer). These findings are in contrast to those of Bennett \& Jarvis (1988), who found an increase in urinary testosterone concentrations at the onset of the breeding season based on serial collections of urine samples from a single male and female throughout the year in laboratory conditions. The non-significant result from our study may be attributed to the small number of male mole-rats captured, and the samples in the two studies are likely to be collected at different time intervals during the breeding season. Male Namaqua dune mole-rats (Bathyergus janetta) and Cape dune mole-rats (Bathyergus suillus), exhibit heightened testosterone concentrations at the onset of the breeding season, which coincides with the winter rains of the northern and western Cape, respectively (Herbst et al. 2004; Hart \& Bennett 2006). Both of these species exhibit two distinct peaks in testosterone levels during the breeding season, one at the beginning of the breeding period and one towards the end. Interestingly, the difference in testosterone concentrations between males in the breeding and nonbreeding seasons was significant for the Cape dune mole-rat, but not so for the Namaqua dune mole-rat (Herbst et al. 2004; Hart \& Bennett 2006).

Female Cape mole-rats displayed higher circu- lating basal oestrogen and progesterone concentrations during the breeding season, but due to large intra-specific variation, this difference was found not to be significant for either of the steroid hormones. High intra-specific variation may stem from the inclusion of samples taken from females that had previously been mated and those that had not. Since the Cape mole-rat is an induced ovulater, coitus may have resulted in some females exhibiting a higher level of steroid hormone compared to those that were unmated (dams). Sharp elevations in oestrogen and progesterone levels were recorded for the Cape dune mole-rat and the Namaqua dune mole-rat (Herbst et al. 2004; Hart \& Bennett 2006) during the onset of the breeding season. In the Cape dune mole-rat, only the progesterone concentration was significantly higher during the breeding season than out of the breeding period (Hart \& Bennett 2006), which may be as a result of the large numbers of early pregnant females. The hormonal concentrations of the Namaqua dune mole-rat were not significantly different in and out of the breeding season (Herbst et al. 2004), which corresponds with the findings of the current study.

The Cape mole-rat is a seasonal breeder, however, the findings of this study support further investigations that have revealed no seasonal differences in GnRH induced LH concentrations in both male and female Cape mole-rats, and no seasonal difference in the GnRH-1immunoreactive neuronal staining in the hypothalamus of female Cape mole-rats (Oosthuizen \& Bennett 2007; Oosthuizen et al. 2008). The lack of seasonal differences at the pituitary and hypothalamic regions, in addition to no seasonal difference in the gonadal hormones, points towards an opportunistic breeding strategy.

Alternatively, the lack of distinct differences in gonadal steroid concentrations in and out of the breeding season may be the result of sampling methods. Animals were captured in August, towards the end of the breeding season. Bennett \& Jarvis (1988) showed the highest testosterone levels to occur in June and July at the onset of the breeding season therefore the males sampled in the present study might well have been captured when hormonal levels were already in decline after the initial part of the breeding season. The onset of winter rainfall in the Cape is around late May, hence if these animals show a similar trend to the Namaqua dune mole-rat, hormonal concentrations would have started to increase soon after 
the first rainfall. However, the Cape mole-rat occurs sympatrically with the Cape dune mole-rat, which also shows a peak in steroid hormone concentrations during August (Hart et al. 2006).

At present, it is uncertain which environmental factor(s) are responsible for the seasonal control of reproduction in subterranean mole-rats. Photoperiod is the primary environmental cue used by aboveground animals to entrain their breeding patterns (Karsch et al. 1984). Mole-rats rarely venture above ground and therefore are not in frequent contact with photoperiodic cues. However, despite a regressed visual system, most mole-rat species are still able to entrain their daily activity rhythms to a circadian light cycle (Oosthuizen et al. 2003; Hart et al. 2004; Vasicek et al. 2005; Schöttner et al. 2006).

Temperatures in the burrow system are reasonably buffered, thus seasonal temperature changes do not fluctuate as much as aboveground (Bennett \& Faulkes 2000). Yet, foraging tunnels close to the surface may relay seasonal temperature changes to mole-rats (Bennett et al. 1988).

Rainfall influences both growth of plants, which affects food availability, and the moisture content of the soil that enables animals to excavate new tunnels (Dennis \& Marsh 1997; Herbst et al. 2004). In addition, gonadal steroid concentrations appear to be well correlated with the rainfall profile. Breeding in the Namaqua dune mole-rat appears to be restricted to the period after the first winter rainfall (Herbst et al. 2004). Considering that in this study, seasonal gonadal hormone concentrations were not found to be significantly different in the Cape mole-rat, it is likely that, physiologically, this rodent mole has the capability to reproduce at any time of the year, but is restricted by unfavourable environmental conditions and in particular restricted times to burrow in search of mates.

\section{ACKNOWLEDGEMENTS}

Mr and Mrs Duckitt of Waylands farm in Darling are thanked for their kindness and hospitality. The research was funded by the National Research Foundation (NCB) a Mellon Mentorship Association (MKO and NCB). Ethics clearance for the project was obtained from the Animal Use and Care Committee of the University of Pretoria (No. AUCC 030110-002).

\section{REFERENCES}

ANDERSEN, D.C. \& MACMAHON, J.A. 1981. Populations dynamics and bioenergetics of a fossorial herbivore, Thomomys talpoides (Rodentia: Geomyidae) in a spruce fir sere. Ecological Monogaphs 51: 179-202.

BENNETT, N.C. \& JARVIS, J.U.M. 1988. The reproductive biology of the Cape mole-rat, Georychus capensis (Rodentia: Bathyergidae). Journal of Zoology London 214: 95-106.

BENNETT, N.C. DAVIES, K JARVIS, J.U.M. \& DAVIES, K.C. 1988. Daily and seasonal temperatures in the burrows of African rodent moles. South African Journal of Zoology 23: 189-195

BENNETT, N.C., FAULKES, C.G. \& MOLTENO, A.J. 1996. Reproductive suppression in subordinate, non-breeding female Damaraland mole-rats: two components to a lifetime of socially induced infertility. Proceedings of the Royal Society London B. Biological Sciences 263: 1599-1603.

BENNETT, N.C. \& FAULKES, C.G. .2000. African Mole-rats: Ecology and Eusociality. Cambridge University Press, Cambridge.

CLARKE, J.R. 1981. Physiological problems of seasonal breeding in eutherian mammals. Oxford Reviews of Reproductive Biology 3: 244-312.

DENNIS, A.J. \& MARSH, H. 1997. Seasonal reproduction in musky rat-kangaroos, Hypsiprymnokon moschatus: a response to changes in resource availability. Wildlife. Research 24: 561-578.

EBLING, F.J.P., MIRAKHUR, A., MAYWOOD, E.S. \& HASTINGS, M.H. 1994. Photoperiodically induced changes in glutaminergic stimulation of LH secretion in male Syrian hamsters: role of circulating testosterone and endogenous opioids. General and Comparative Endocrinology 96: 50-62.

FOLIN, O. 1914. On the determination of creatinine and creatine in the urine. Journal of Biology and Chemistry 17: 469-473.

HART, L., BENNETT, N.C., MALPAUX, B., CHIMIMBA, C.T. \& OOSTHUIZEN, M.K. 2004. The chronobiology of the Natal mole-rat, Cryptomys hottentotus natalensis. Physiology and Behavior 82: 563-569.

GERLACH, T. \& AURICH, J.E. 2000. Regulation of seasonal reproductive activity in the stallion, ram and hamster. Animal Reproductive Science 58: 197-213.

HANSEN, R.M. 1960. Age and reproductive characteristics of mountain pocket gophers in Colorado. Journal of Mammalogy 41: 323-335.

HART, L. \& BENNETT, N.C. 2006. The pituitary potential for opportunistic breeding in the Cape dune molerat, Bathyergus suillus. Physiology and Behavior 88: 615-619.

HERBST, M., JARVIS, J.U.M. \& BENNETT, N.C. 2004. A field assessment of reproductive seasonality in the threatened wild Namaqua dune mole-rat (Bathyergus janetta). Journal of Zoology London 263: 259-268.

JARVIS, J.U.M. (1969) The breeding season and litter size of African mole-rats. Journal of Reproductive Fertility, Suppl. 6: 237-248.

KARSCH, F.J., BITTMAN, E.L., FOSTER, D.L., GOODMAN, R.L., LEGAN, S.J. \& ROBINSON, J.E. 1984. Neuroendocrine basis for seasonal reproduction. Recent Progress in Hormone Research 40: 185-225.

KARSCH, FJ., DAHL, G.E., EVANS, N.P., MANNING, J.M., MAYFIELD, K.P., MOENTER, S.M. \& FOSTER, D.L. 1993. Seasonal changes in gonadotropin releasing hormone secretion in the ewe: alteration in response to negative feedback action of estradiol. 
Biology of Reproduction 49: 1377-1383.

KNOBIL, E.N.J.D. 1988. Physiology of Reproduction. Raven Press, New York.

KOENIG, W.D., PITELKA, F.A., CARMEN, W.J., MUMME, R.L. \& STANBACK, M.T. 1992. The evolution of delayed dispersal in cooperative breeders. Quarterly Review of Biology 67(2): 111-150.

LINCOLN, G.A. 1984. Central effects of photoperiod on reproduction in the ram revealed by the use of a testosterone clamp. Journal of Endocrinology 103: 233-244.

NEVO, E. 1979. Adaptive convergence and divergence in subterranean mammals. Annual Review of Ecological Systematics 10: 269-308.

OOSTHUIZEN, M.K., BENNETT, N.C. \& COOPER, H.M. 2003. Circadian rhythms of locomotor activity in solitary and social species of African mole-rats (family: Bathyergidae). Journal of Biological Rhythms 18(6): 481-490.

OOSTHUIZEN, M.K. \& BENNETT, N.C. 2007. LH responses to single doses of exogenous $\mathrm{GnRH}$ in the Cape mole-rat (Georychus capensis): the pituitary potential for opportunistic breeding. Journal of Zoology 271: 198-202.

OOSTHUIZEN, M.K., BENNETT, N.C. \& COEN, C.W. 2008. An immunohistochemical study of the gonadotrophin-releasing hormone 1 system in solitary Cape mole-rats, Georychus capensis, and social Natal mole-rats, Cryptomys hottentotus natalensis. Neuroscience 157: 164-173.

RADO, R., WOLLBERG, Z. \& TERKEL, J. 1992. Dispersal of young mole-rats (Spalax ehrenbergi) from the natal burrow. Journal of Mammalogy 73: 885-890.

SCHMIDT-NIELSEN, K. 1997. Animal Physiology: Adaptation and Environment, 5th edn. Cambridge University Press.

SCHÖTTNER, K., OOSTHUIZEN, M.K., BROEKMAN, M.S. \& BENNETT, N.C. 2006. Circadian rhythms of locomotor activity in the Lesotho mole-rat, Cryptomys hottentotus subspecies from Sani Pass, South Africa. Physiology and Behavior 89(2): 205-12.

VAN SANDWYK, J.DT. \& BENNETT, N.C. 2005. Do solitary, seismic signaling Cape mole-rats, Georychus capensis demonstrate spontaneous or induced ovulation? Journal of Zoology London 267: 75-80.

VASICEK, C.A., OOSTHUIZEN, M.K., COOPER, H.M., BENNETT, N.C. 2005. Circadian rhythms of locomotor activity in the subterranean Mashona mole-rat Cryptomys darlingi. Physiology and Behavior 84: 181191.

VAUGHAN, T.A. (1962) Reproduction in plains pocket gopher in Colorado. Journal of Mammalogy 43: 1-13.

Responsible Editor: G.N. Bronner 